\title{
ONE-YEAR CLINICAL OUTCOMES IN INDIAN PATIENTS UNDERGOING PRIMARY PERCUTANEOUS CORONARY INTERVENTION WITHOUT ON-SITE SURGICAL BACKUP
}

\author{
George Mathew Neeraakal', Jayakumar Thankamani Gopinathan²
}

${ }^{1}$ Consultant Cardiologist, Department of Cardiology, Edappal Hospital Pvt. Ltd., Edappal, Malappuram, Kerala, India.

${ }^{2}$ Consultant Cardiologist, Department of Cardiology, Edappal Hospital Pvt. Ltd., Edappal, Malappuram, Kerala, India.

\begin{abstract}
BACKGROUND
ABSTRACT

Primary Percutaneous Coronary Intervention (PCI) has emerged as a relatively safe treatment option for acute ST elevation myocardial infarction. However, performing primary PCI at centres without surgical backup has been controversial. To the be st of our knowledge, no such data has been available that represents outcomes in Indian population.

Thus, this study aims to present one year clinical outcomes in Indian patients undergoing primary PCI without on-site surgical backup.
\end{abstract}

\section{MATERIALS AND METHODS}

This was a retrospective, single centre, observational study. The study population included 192 patients, who underwent primary PCI from February 2014 to July 2015. The primary endpoint was rate of Major Adverse Cardiac Events (MACE), an agglomerate of cardiac death, myocardial infarction and Target Vessel Revascularisation (TLR) at one year after procedure.

\section{RESULTS}

The mean age of population was 57.2 years where $86.5 \%$ were males, $35.4 \%$ were diabetics and $22.4 \%$ were hypertensives. There were six cardiac deaths at 30-day follow-up and 6 (3.1\%) cardiac deaths and 4 (2.1\%) events of TLR at one-year follow-up.

\section{CONCLUSION}

In light of these results, it can be concluded that primary PCI can be performed safely at PCI centres without on-site surgical backup, especially in developing countries like India.

\section{KEY WORDS}

Coronary Artery Disease, Percutaneous Coronary Intervention, ST Elevation Myocardial Infarction.

HOW TO CITE THIS ARTICLE: Neeraakal GM, Gopinathan JT. One-year clinical outcomes in Indian patients undergoing primary percutaneous coronary intervention without on-site surgical backup. J. Evolution Med. Dent. Sci. 2018;7(33):3674-3678, DOI: $10.14260 /$ jemds/2018/825

\section{BACKGROUND}

Acute ST elevation Myocardial Infarction (AMI) has been one of the major causes of death throughout the world, especially in developing countries. At inception, the procedure of balloon angioplasty for treatment of CAD was time consuming as well as associated with augmented rate of complications. Therefore, it mandated the requirement of emergency coronary artery bypass graft surgery (CABG) at the site of angioplasty.[1] However, with the elapse of time the development of new generation stents have led to decrease in reperfusion time, thus resulting in decreased infarct size and reduced incidence of Major Adverse Cardiac Events (MACE). Advancement in interventional cardiology techniques, equipment and pharmacology has contributed towards such diminution of complications, thus leading to reduction in need for emergency CABG at Percutaneous Coronary Intervention (PCI) centres. ${ }^{[2]}$ Due to finesse in operators and facilities, the requirement of emergency CABG during PCI has been limited to only 0.3 to $0.6 \%$ of total cases.[1,3]

'Financial or Other Competing Interest': None.

Submission 29-06-2018, Peer Review 30-07-2018,

Acceptance 06-08-2018, Published 13-08-2018.

Corresponding Author:

Dr. George Mathew Neeraakal,

Consultant Cardiologist,

Edappal Hospital Pvt. Ltd.,

Edappal, Malappuram-679576, Kerala, India.

E-mail: drgeorgemathewn@hotmail.com

DOI: $10.14260 /$ jemds $/ 2018 / 825$

\section{(c) (i) $\$$}

On the darker side, 2004 American College of Cardiology/ American Heart Association practice guidelines for ST Segment Elevation Myocardial Infarction (STEMI) had recommended Class IIb for primary PCI in centres without cardiac surgery. ${ }^{[4]}$ The 2011 ACCF/AHA/SCAI guidelines has suggested that primary PCI can be performed in hospitals without on-site surgical back-up, only with apt planning for program development (Class IIa).

However, without a proper plan for prompt shifting to a nearby cardiac surgery hospital or without suitable haemodynamic support capability for transfer, the guideline has recommended Class III.[5] Despite conflicting literature, the number of PCIs performed at centres without on-site surgical backup have been progressively increasing through years, such that several studies have been performed to compare the safety and effectiveness of PCI at PCI centres without on-site surgical backup and those with on-site CABG backup. [6-13] These studies reported no significant difference in outcomes of PCI between both centres at various follow-up periods. However, to the best of our knowledge, none of such study has been reported in India. Thus, this study aimed to present one-year clinical outcomes in Indian patients undergoing primary PCI without on-site surgical backup.

\section{MATERIALS AND METHODS}

Study design and patient's population.

This was a retrospective, single centre, observational study which included 192 patients who underwent primary 
PCI at our institute between February 2014 and July 2015. Baseline demographics, cardiac history and angiographic data were collected from patient's medical records and follow-up data were recorded prospectively. Before the discharge of the patient from the hospital, data release consent was taken from every patient, irrespective of any study to be conducted in future. The study has been approved by the Institutional Ethics Committee.

Patients admitted with acute ST elevation myocardial infarction were included in the study. Patients with significant co-morbidities like severe renal or liver impairment with contraindications for dual antiplatelet therapy for one year with major or advanced malignancies which limit the longevity of life and those who refused to give informed consent were not included in the study.

\section{Endpoints of the Study}

The primary endpoint of the study was occurrence of MACE, an agglomerate of cardiac death, myocardial infarction and target vessel revascularisation at one year after primary PCI. Furthermore, the occurrence of stent thrombosis was also evaluated. Any death because of MI, low-output failure, fatal arrhythmia, unwitnessed death and death due to unknown reason and all procedure-related deaths, encompassing those associated to concomitant treatment were categorised as cardiac death.[14] The MI was described as increase of cardiac troponin (cTn) levels $\{>5 \times 99$ th percentile of Upper Reference Limit (URL)\} in patients with normal baseline levels ( $\leq 99$ th percentile URL) or rise of cTn levels $>20 \%$ when baseline values are high and stable or decreasing.[15] Pathological Q-waves are defined with reference to amplitude, location and depth in minimum two contiguous leads. A TLR was referred to restenosis within stent or within $5 \mathrm{~mm}$ distal or proximal segment.[14]

\section{PCI Procedure}

The PCI was performed by a standard percutaneous technique through the radial or femoral artery. Aspirin (325 mg upon arrival and then $100 \mathrm{mg}$ daily), clopidogrel (loading dose of 300 or $600 \mathrm{mg}$ and then $75 \mathrm{mg}$ daily) were administered to every patient and an IV bolus of unfractionated heparin $(100 \mathrm{U} / \mathrm{kg}$ body weight or $60 \mathrm{U} / \mathrm{kg}$ body weight if also GP IIb/IIla inhibitors was given) was also given. The choice of treatment modality between DrugEluting Stent (DES) versus Bare Metal Stent (BMS) or Plain Old Balloon Angioplasty (POBA) and the use of an intra-aortic balloon pump or glycoprotein IIb/IIIa inhibitors was left to the discretion of the interventional cardiologist. Moreover, thrombectomy was performed in each patient.

\section{Follow-Up}

Follow-up data up to one-year post PCI were collected through the medical records, clinical visit to hospital or telephonically. Follow-ups were carried out to establish the major cardiac adverse events at 30 days, 6 months and one year.

\section{Statistical Analysis}

Means and Standard Deviations (SD) were calculated for quantitative variables. Categorical variables were reported as counts and percentages. Cumulative incidences of events were calculated using Kaplan-Meier method. All statistical analyses were completed using the Statistical Package for Social Sciences Software (Version 15.0, SPSS, Chicago).

\section{RESULTS}

Out of 192 patients, 166 (86.5\%) were males and mean age of all patients was 57.2 years. Sixty-eight (35.4\%) patients were diabetics and 43 (22.4) were hypertensives. The average ejection fraction was $50.6 \pm 11.0 \%$. Glomerular filtration rate was less than $60 \mathrm{~mL} / \mathrm{min} / 1.73 \mathrm{~m}^{2}$ in $20(10.4 \%)$ patients. The baseline characteristics have been detailed in Table 1.

There were total 195 lesions in 192 patients, of which 102 (52.3\%) lesions were located in left anterior descending artery, 70 (35.9\%) in right coronary artery, $22(11.3 \%)$ in left circumflex artery and $1(0.5 \%)$ in left main artery. Forty-nine (25.5\%) patients had triple vessel disease (Table 2). Right femoral route was the most preferred approach for $\mathrm{PCI}$ (97.9\%). Direct stenting was performed in 26 (13.3\%) lesions. Drug Eluting Stents (DES) were implanted in 143 $(73.3 \%)$ lesions, BMS in $25(12.8 \%)$ and POBA was performed in 27 (13.8\%) lesions. TIMI 3 flow was achieved in $182(93.3 \%)$ lesions (Table 3).

Six $(3.1 \%)$ cardiac deaths occurred within 30 days of procedure. At one-year follow-up MACE rate was 5.2\%, which included $6(3.1 \%)$ cardiac deaths and $4(2.1 \%)$ TLR. There were total 4 incidences of stent thrombosis at one year follow-up (Table 4). Kaplan-Meier curve for cumulative incidences of cardiac deaths and MACE at one year have been depicted in Figure 1 and Figure 2.

\begin{tabular}{|c|c|}
\hline Characteristics & Patients $(\mathrm{N}=192)$ \\
\hline Age (mean \pm SD, years) & $57.2 \pm 12.1$ \\
\hline Male, n (\%) & $166(86.5 \%)$ \\
\hline BMI $\left(\right.$ mean $\left.\pm \mathrm{SD}, \mathrm{kg} / \mathrm{m}^{2}\right)$ & $21.8 \pm 1.8$ \\
\hline SBP (mean \pm SD, mmHg) & $138.6 \pm 33.1$ \\
\hline DBP $($ mean \pm SD, $\mathrm{mmHg}$ ) & $83.5 \pm 16.5$ \\
\hline $\begin{array}{l}\text { Random Blood Sugar (mean } \pm \text { SD, } \\
\mathrm{mmol} / \mathrm{L})\end{array}$ & $174.6 \pm 79.8$ \\
\hline Diabetes mellitus, n (\%) & $68(35.4 \%)$ \\
\hline Hypertension, n (\%) & $43(22.4 \%)$ \\
\hline Hypercholesterolaemia, n (\%) & $5(2.6 \%)$ \\
\hline Smoking, n (\%) & $37(19.3 \%)$ \\
\hline Cardiogenic shock, n (\%) & $7(3.6 \%)$ \\
\hline Complete heart block, n (\%) & $11(5.7 \%)$ \\
\hline VT or VF, n (\%) & $8(4.2 \%)$ \\
\hline $\mathrm{AF}, \mathrm{n}(\%)$ & $2(1.0 \%)$ \\
\hline Ejection fraction (mean \pm SD, \%) & $50.6 \pm 11.0$ \\
\hline Reinfarction, n (\%) & $3(1.6 \%)$ \\
\hline Bleeding, $\mathrm{n}(\%)$ & $4(2.1 \%)$ \\
\hline Renal insufficiency at screening, n (\%) & $12(6.3 \%)$ \\
\hline Cerebral vascular accident, n (\%) & $1(0.5 \%)$ \\
\hline Pericarditis, n (\%) & $1(0.5 \%)$ \\
\hline LVF pulmonary oedema, n (\%) & $5(2.6 \%)$ \\
\hline GFR $<60 \mathrm{~mL} / \mathrm{min} / 1.73 \mathrm{~m}^{2}, \mathrm{n}(\%)$ & $20(10.4 \%)$ \\
\hline
\end{tabular}

Table 1. Baseline demographic characteristics of Patients

BMI- Body Mass Index, SBP- Systolic Blood Pressure, DBPDiastolic Blood Pressure, VT- Ventricular Tachycardia, VFVentricular Fibrillation, AF- Atrial Fibrillation, LVF- Left Ventricular Failure, GFR- Glomerular Filtration Rate. 


\begin{tabular}{|c|c|}
\hline Characteristics & Patients (N= 192)/ Lesions (N= 195) \\
\hline \multicolumn{2}{|c|}{ Myocardial Infarction } \\
\hline STEMI, n (\%) & $192(100 \%)$ \\
\hline \multicolumn{2}{|c|}{ Target Vessel } \\
\hline LM, n (\%) & $1(0.5 \%)$ \\
\hline LAD, n (\%) & $102(52.3 \%)$ \\
\hline LCX, n (\%) & $22(11.3 \%)$ \\
\hline RCA, n (\%) & $70(35.9 \%)$ \\
\hline \multicolumn{2}{|c|}{ Number of Diseased Vessel } \\
\hline SVD, n (\%) & $76(39.6 \%)$ \\
\hline DVD, n (\%) & $67(34.9 \%)$ \\
\hline TVD, n (\%) & $49(25.5 \%)$ \\
\hline \multicolumn{2}{|c|}{ Table 2. Lesion characteristics of Patients } \\
\hline
\end{tabular}

STEMI- ST-Elevation Myocardial Infarction, LM- Left Main, LAD- Left Anterior Descending Artery, LCX- Left Circumflex Artery, RCA- Right Coronary Artery, SVD- Single Vessel Disease, DVD- Double Vessel Disease, TVD- Triple Vessel Disease.

\begin{tabular}{|c|c|}
\hline Characteristics & $\begin{array}{l}\text { Patients } \\
(\mathrm{N}=192)\end{array}$ \\
\hline Right femoral approach, n (\%) & $188(97.9 \%)$ \\
\hline Right radial approach, n (\%) & $4(2.1 \%)$ \\
\hline Intra-aortic balloon pump, n (\%) & $2(1.0 \%)$ \\
\hline Procedure time $($ mean $\pm \mathrm{SD}, \mathrm{mm})$ & $67.0 \pm 23.9$ \\
\hline Fluoroscopy time (mean \pm SD, mm) & $52.6 \pm 21.8$ \\
\hline Direct stenting, n (\%) & $26(13.3 \%)$ \\
\hline Temporary pacemaker implant, n (\%) & $26(13.5 \%)$ \\
\hline \multicolumn{2}{|l|}{ Stent } \\
\hline BMS, n (\%) & $25(12.8 \%)$ \\
\hline DES, n (\%) & $143(73.3 \%)$ \\
\hline POBA, n (\%) & $27(13.8 \%)$ \\
\hline Average stent length (mean \pm SD, mm) & $25.3 \pm 7.1 \mathrm{~mm}$ \\
\hline Average stent diameter (mean $\pm \mathrm{SD}, \mathrm{mm})$ & $3.2 \pm 0.3 \mathrm{~mm}$ \\
\hline \multicolumn{2}{|l|}{ Post TIMI flow } \\
\hline TIMI 0, n (\%) & $0(0 \%)$ \\
\hline TIMI 1, n (\%) & $5(2.6 \%)$ \\
\hline TIMI 2, n (\%) & $8(4.1 \%)$ \\
\hline TIMI 3, n (\%) & $182(93.3 \%)$ \\
\hline
\end{tabular}

POBA- Plain Old Balloon Angioplasty, BMS- Bare Metal Stents, DES- Drug Eluting Stents, TIMI- Thrombolysis In Myocardial Infarction.

\begin{tabular}{|c|c|c|c|}
\hline Clinical Outcomes & $\begin{array}{c}\text { At 30 Days } \\
\text { Follow-up }\end{array}$ & $\begin{array}{c}\text { At 6 Months } \\
\text { Follow-up }\end{array}$ & $\begin{array}{c}\text { At 1 Year } \\
\text { Follow-up }\end{array}$ \\
\hline $\begin{array}{c}\text { Death from any } \\
\text { cause, n (\%) }\end{array}$ & $6(3.1 \%)$ & $6(3.1 \%)$ & $7(3.6 \%)$ \\
\hline Cardiac death, n (\%) & $6(3.1 \%)$ & $6(3.1 \%)$ & $6(3.1 \%)$ \\
\hline $\begin{array}{c}\text { Non-cardiac death, } \\
\text { n (\%) }\end{array}$ & $0(0 \%)$ & $1(0.5 \%)$ & $1(0.5 \%)$ \\
\hline $\begin{array}{c}\text { Myocardial } \\
\text { infarction, n (\%) }\end{array}$ & $0(0 \%)$ & $0(0 \%)$ & $0(0 \%)$ \\
\hline $\begin{array}{c}\text { Target lesion } \\
\text { revascularisation, } \\
\text { n (\%) }\end{array}$ & $1(0.5 \%)$ & $3(1.6 \%)$ & $4(2.1 \%)$ \\
\hline $\begin{array}{c}\text { Target vessel } \\
\text { revascularisation, } \\
\mathrm{n}(\%)\end{array}$ & $3(1.6 \%)$ & $5(2.6 \%)$ & $9(4.7 \%)$ \\
\hline
\end{tabular}

\begin{tabular}{|c|c|c|c|}
\hline $\begin{array}{c}\text { Stent thrombosis, } \\
\text { n (\%) }\end{array}$ & $2(1.0 \%)$ & $2(1.0 \%)$ & $4(2.1 \%)$ \\
\hline $\begin{array}{c}\text { Major adverse } \\
\text { cardiac events, } \\
\text { n (\%) }\end{array}$ & $7(3.6 \%)$ & $9(4.7 \%)$ & $10(5.2 \%)$ \\
\hline \multicolumn{3}{|c|}{$\begin{array}{r}\text { Table 4. Clinical outcomes of 192 } \\
\text { patients after Primary PCI }\end{array}$} \\
\hline
\end{tabular}

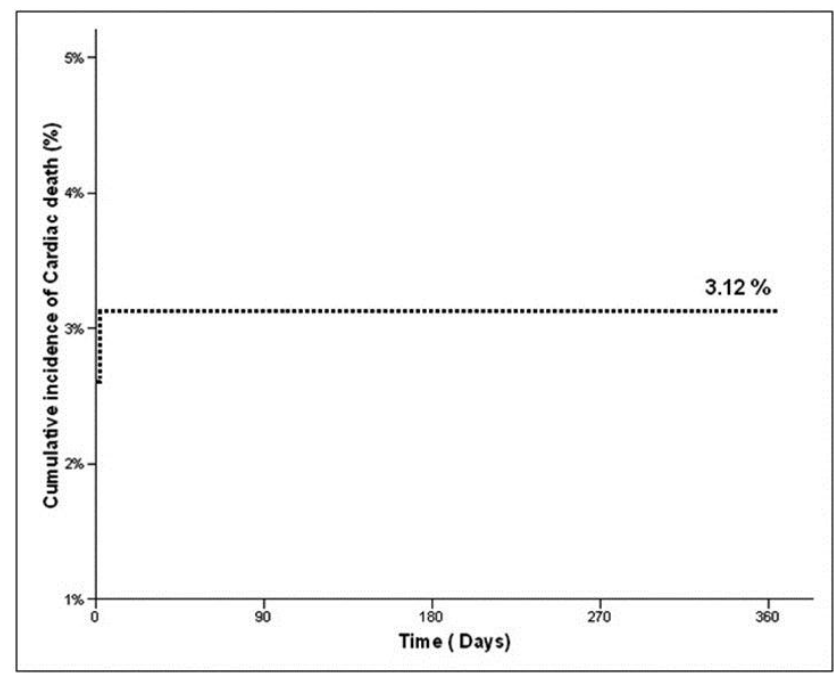

Figure 1. Cumulative Incidence of Cardiac Death upto 1 Year

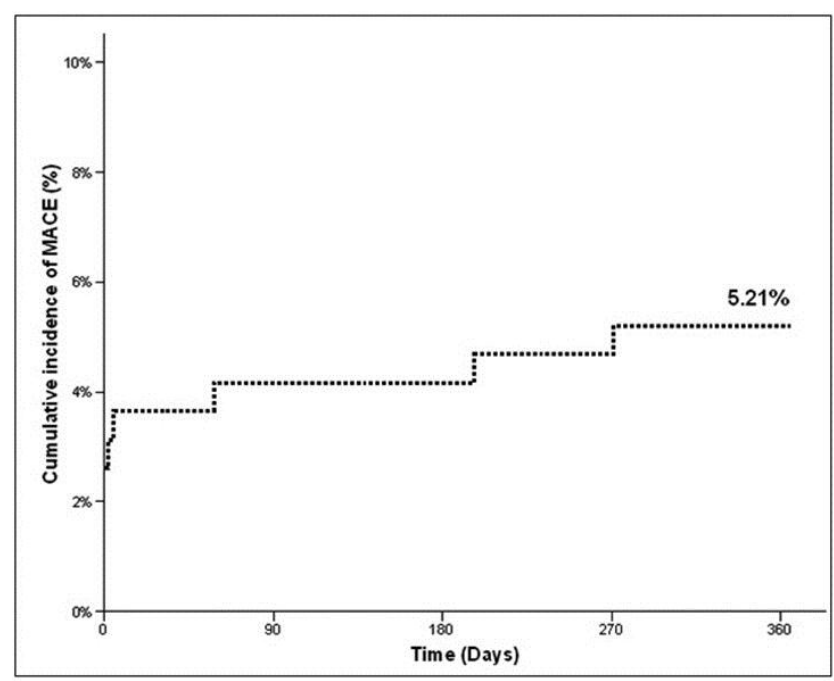

Figure 2. Cumulative Incidence of MACE at 1 Year

\section{DISCUSSION}

The developments in PCI have been a crucial boon as these have eliminated the complications due to balloon angioplasty, thus leading to wane the role of surgical backup. Major concern related to PCI without on-site surgical backup was the early mortality rate, i.e. in-hospital mortality and 30-day mortality rate. Various studies have compared the early mortality rates at on-site PCI centres and centres without onsite surgical backup. Recently, Koolen et al had compared MACE rates between the off-site PCI and on-site PCI procedures at 30 days and 6 months follow-up. Cardiac deaths within 30 days for the off-site PCI group and on-site PCI group were $2.3 \%$ and $1.8 \%$, respectively $(\mathrm{p}=1.000)$ While, the cardiac deaths at six months were $2.4 \%$ and $1.8 \%$, respectively.[16] However, there are studies which have reported range of in-hospital deaths without surgical backup 
to be widespread between $4 \%$ and $9.8 \% .^{[9,17]}$ A study in United Kingdom had reported the favour of off-site surgical cover in terms of 30-day mortality (HR: $0.87 ; 95 \% \mathrm{CI}: 0.71$ 1.06; $\mathrm{p}=0.16$ ) and at 1 year mortality (HR: 0.92; 95\% CI: 0.71 - 1.06; $p=0.26$ ) in patients with any indication, but lacked statistical significance.[18] Similarly, a report from National Cardiovascular Data Registry had stated observance of similar procedure's success, morbidity, emergency cardiac surgery rates and mortality in PCI centres without on-site surgical backup and in cases that required emergency surgery.[19] In a meta-analysis, Simard $\mathrm{T}$ et al had observed that primary PCI as well as elective PCI could be performed safely at PCI centres without on-site surgical backup, without an increase in mortality rates or other complications.[2] In present study, the mortality rate at 30 days was $3.1 \%$, which was parallel to the results of clinical trials for primary PCI which represent early death rates of $<5 \%$.[20-22] While the real world registries (irrespective of on-site procedures or procedures without on-site surgical backup) exhibit higher mortality rates ranging from $7 \%$ to $10.5 \% .^{[23-25]}$ Thus, it can be conferred that the availability of surgical backup does not chiefly affect the early mortality rates.

Furthermore, the literature states that coronary reperfusion should be achieved at the earliest as mortality is closely allied to the time delay between symptom onset and reperfusion.[26] Thus, mortality has been a major dependent of time delay rather than availability of surgical backup. In view of this, a door-to-balloon time of $\leq 90 \mathrm{mins}$ is recommended to achieve optimal results.[27] Accordingly, in developing countries like India where it has been difficult for rural population to reach out at the hospitals during emergency, in such cases the availability of PCI centres at community hospitals without on-site surgical backup would be of immense benefit in terms of avoiding delay in reperfusion time. Establishment of such PCI centres will enable more patients to utilise the benefits of PCI. On the other hand, taking into consideration the finesse of operator and patient's selection is also equally important, such that the patients could get full benefit of the facilities.

\section{Limitations}

There are some limitations of this study. First of all, it lacks a comparative arm. Secondly, this study represents a retrospective data. Third, the data are derived from a single centre.

\section{CONCLUSION}

In light of these results, it can be concluded that primary PCI can be performed safely at PCI centres without on-site surgical backup, especially in developing countries like India. However, adequate facilities at centres, availability of skilled operators and apt patient selection must be taken into consideration.

\section{REFERENCES}

[1] Yang EH, Gumina RJ, Lennon RJ, et al. Emergency coronary artery bypass surgery for percutaneous coronary interventions: changes in the incidence, clinical characteristics, and indications from 1979 to 2003. J Am Coll Cardiol 2005;46(11):2004-9.
[2] Simard T, Hibbert B, Pourdjabbar A, et al. Percutaneous coronary intervention with or without on-site coronary artery bypass surgery: a systematic review and meta-analysis. Int J Cardiol 2013;167(1):197-204.

[3] Seshadri N, Whitlow PL, Acharya N, et al. Emergency coronary artery bypass surgery in the contemporary percutaneous coronary intervention era. Circulation 2002;106(18):2346-50.

[4] Antman EM, Anbe DT, Armstrong PW, et al. ACC/AHA guidelines for the management of patients with STelevation myocardial infarction-executive summary: a report of the American College of Cardiology/American Heart Association Task Force on Practice Guidelines (Writing Committee to Revise the 1999 Guidelines for the Management of Patients With Acute Myocardial Infarction). Circulation 2004;110(5):588-636.

[5] Levine GN, Bates ER, Blankenship JC, et al. 2011 ACCF/AHA/SCAI guideline for percutaneous coronary intervention a report of the American College of Cardiology Foundation/American Heart Association Task Force on Practice Guidelines and the Society for Cardiovascular Angiography and Interventions. Circulation 2011;124(23):e574-651.

[6] Shahian DM, Meyer GS, Yeh RW, et al. Percutaneous coronary interventions without on-site cardiac surgical backup. N Engl J Med 2012;366:1814-23.

[7] Tebbe U, Hochadel M, Bramlage P, et al. In-hospital outcomes after elective and non-elective percutaneous coronary interventions in hospitals with and without on-site cardiac surgery backup. Clin Res Cardiol 2009;98(11):701-7.

[8] Hannan EL, Zhong Y, Racz M, et al. Outcomes for patients with ST-Elevation myocardial infarction in hospitals with and without onsite coronary artery bypass graft surgery: The New York State Experience. Circ Cardiovasc Interv 2009;2:519-27.

[9] Ting HH, Raveendran G, Lennon RJ, et al. A total of 1 , 007 percutaneous coronary interventions without onsite cardiac surgery: acute and long-term outcomes. J Am Coll Cardiol 2006;47(8):1713-21.

[10] Tomassini F, Gagnor A, Montali N, et al. Primary percutaneous coronary intervention without on-site cardiac surgery backup in unselected patients with STsegment-elevation myocardial infarction: the Rivoli ST-segment elevation myocardial infarction (RISTEMI) registry. Cardiovasc Revasc Med 2013;14(1):9-13.

[11] Singh M, Holmes DR Jr, Dehmer GJ, et al. Percutaneous coronary intervention at centers with and without onsite surgery: a meta-analysis. JAMA 2011;306(22):2487-94.

[12] Mol KA, Rahel B, Eerens F, et al. The first year of the Venlo percutaneous coronary intervention program: procedural and 6-month clinical outcomes. Neth Heart J 2013;21(10):449-55.

[13] Peels JO, Hautvast RW, de Swart JB, et al. Percutaneous coronary intervention without on site surgical backup: two-years registry of a large Dutch community hospital. Int J Cardiol 2009;132(1):59-65. 
[14] Cutlip DE, Windecker S, Mehran R, et al. Clinical end points in coronary stent trials: a case for standardized definitions. Circulation 2007;115(17):2344-51.

[15] Thygesen K, Alpert JS, Jaffe AS, et al. Third universal definition of myocardial infarction. Eur Heart J 2012;33(20):2551-67.

[16] Koolen KH, Mol KA, Rahel BM, et al. Off-site primary percutaneous coronary intervention in a new centre is safe: comparing clinical outcomes with a hospital with surgical backup. Neth Heart J 2016;24(10):581-8.

[17] Pride YB, Canto JG, Frederick PD, et al. Outcomes among patients with ST-segment-elevation myocardial infarction presenting to interventional hospitals with and without on-site cardiac surgery. Circ Cardiovasc Qual Outcomes 2009;2(6):574-82.

[18] Garg S, Anderson SG, Oldroyd K, et al. Outcomes of percutaneous coronary intervention performed at offsite versus onsite surgical centers in the United Kingdom. J Am Coll Cardiol 2015;66(4):363-72.

[19] Kutcher MA, Klein LW, Ou F-S, et al. Percutaneous coronary interventions in facilities without cardiac surgery on site: a report from the National Cardiovascular Data Registry (NCDR). J Am Coll Cardiol 2009;54(1):16-24.

[20] Stone GW, Witzenbichler B, Guagliumi G, et al. Bivalirudin during primary PCI in acute myocardial infarction. N Engl J Med 2008;358(21):2218-30.

[21] Stone GW, Grines CL, Cox DA, et al. Comparison of angioplasty with stenting, with or without abciximab, in acute myocardial infarction. $N$ Engl J Med 2002;346(13):957-66.

[22] Valgimigli M, Campo G, Percoco G, et al. Comparison of angioplasty with infusion of tirofiban or abciximab and with implantation of sirolimus-eluting or uncoated stents for acute myocardial infarction: the MULTISTRATEGY randomized trial. JAMA 2008;299(15):1788-99.
[23] Carlsson J, James SN, Ståhle E, et al. Outcome of percutaneous coronary intervention in hospitals with and without on-site cardiac surgery standby. Heart 2007;93(3):335-8.

[24] Di Chiara A, Chiarella F, Savonitto S, et al. Epidemiology of acute myocardial infarction in the Italian CCU network: the BLITZ study. Eur Heart J 2003;24(18):1616-29.

[25] Shiraishi J, Kohno Y, Sawada T, et al. In-hospital outcomes of primary percutaneous coronary interventions performed at hospitals with and without on-site coronary artery bypass graft surgery. Circ J 2007;71(8):1208-12.

[26] De Luca G, Suryapranata H, Ottervanger JP, et al. Time delay to treatment and mortality in primary angioplasty for acute myocardial infarction: every minute of delay counts. Circulation 2004;109(10):1223-5.

[27] Kushner FG, Hand M, Smith SC Jr, et al. 2009 Focused Updates: ACC/AHA guidelines for the management of patients with ST-Elevation myocardial infarction (Updating the 2004 Guideline and 2007 Focused Update) and ACC/AHA/SCAI guidelines on percutaneous coronary intervention (Updating the 2005 Guideline and 2007 Focused Update). A Report of the American College of Cardiology Foundation/American Heart Association Task Force on Practice Guidelines. Circulation 2009;120(22):2271-306. 